\title{
CLINICO-SOCIAL AND IMMUNOLOGICAL PROFILE OF ANTIRETROVIRAL NAÏVE CHILDREN LIVING WITH HIV IN TERTIARY CARE HOSPITAL, DELHI
}

\author{
Verma D1, Acharya AS ${ }^{1}$, Bachani $D^{1}$, Seth $A^{2}$ \\ 1Department of Community Medicine, Lady Hardinge Medical College \& Associated Hospitals \\ 2Department of Paediatrics, Kalawati Saran Children Hospital
}

\begin{abstract}
Introduction: This study was undertaken to assess the clinical profile of children living with HIV at the time of their enrolment in an ART centre in Delhi. The study also attempts to understand association between clinical staging and immunological profile (CD4 count/percentage) in HIV infected children. The findings of this study may help policy makers to plan better health care of CLHIV in resource constrained country like India. The Objectives of the study were to assess the baseline clinico-social and immunological profile of HIV positive children before the start of Antiretroviral Therapy, to study clinicosocial and morbidity profile of HIV positive children at the time of their enrolment in ART centre and to study the association between immunodeficiency and clinical staging of CLHIV.
\end{abstract}

Methodology: The present study, conducted between December 2012 and March 2013, is a retrospective case review of 83 antiretroviral naïve Children living with HIV aged 8 months to 13 years and attending paediatric ART clinic of a tertiary care hospital of Delhi. After the infection was established on serological grounds, information on socio-demographic, clinical and immunological profile was studied.

Results: Majority (62.7\%) of CLHIV were boys. Both parents of CLHIV were found to be positive in $63.9 \%$ while mother was found to be positive in $69.9 \%$. The most common route of HIV infection was mother-to-child transmission (69.9\%), followed by transmission though blood/blood products (12.0\%). Every three out of four children $(71.1 \%)$ were in WHO clinical stage III or IV. Three out of four $(74.7 \%)$ children presented with fever, one in two with cough (56.6\%). Diarrhoea (56.6\%), pneumonia $(41.0 \%)$, popular pruritic eruptions $(18.1 \%)$, candidiasis (16.9\%) and tuberculosis (14.5\%) were the most common opportunistic infections in these children. The most common signs present were hepatomegaly (81.9\%), anaemia $(78.3 \%)$ and lymphadenopathy $(72.3 \%)$.

Conclusion: Mother to child transmission is the most common route of transmission in CLHIV. At enrolment more than half of the children were in clinical stage III\&IV. Fever, cough, diarrhoea, weight loss, rashes were common morbidities of the children. Majority of the children had hepatomegaly, anaemia and lymphadenopathy.

Key Words: AIDS;HIV; Opportunistic Infections; Immunodeficiency

\section{INTRODUCTION}

Globally, an estimated 35.3 (32.2-38.8) million people were living with HIV (PLHIV) in 2012, among which 3.2 million were children with a prevalence

\section{Correspondence:}

Dr. Anita Shankar Acharya

Professor

Department of Community Medicine

Lady Harginge Medical College \& Smt. S. K. Hospital New

Delhi - 110001 , India.

E-mail: anitaacharya29@gmail.com of $0.8 \% .{ }^{1}$ It is now estimated that half of all new episodes of HIV transmission in children occur during the breastfeeding period, when the majority of HIV positive lactating women may not be receiving the prophylaxis necessary for prevention of mother to child transmission (PMTCT) of HIV. India has the third largest number of PLHIV and their estimated number in 2011 was 2.09million. Children less than 15 years of age accounted for $7 \%$ ( 0.145 million) of all HIV infections. ${ }^{2}$ The proportional contribution of the number of children living with HIV (CLHIV) out of the total PLHIV population was estimated to be $6.3 \%$ in 2007 and $7 \%$ in $2011 .{ }^{3}$ 
Dysfunction of immune system and resultant illnesses is more rapid in HIV infected children as compared to adults. HIV affects virtually all the systems of the body and presents with varied clinical manifestations. Children with AIDS present with disease patterns that are different in nature, severity and/or frequency as compared to immunecompetent children. The clinical presentation varies with the degree of immune-suppression, ranging from asymptomatic infection to AIDS characterized by severe immuno-suppression and recurrent severe opportunistic infections.

This study was undertaken to assess the clinical profile of children living with HIV at the time of their enrolment in an ART centre in Delhi. The study also attempts to understand association between clinical staging and immunological profile (CD4 count/percentage) in HIV infected children. The findings of this study may help policy makers to plan better health care of CLHIV in resource constrained country like India.

\section{METHODOLOGY}

The present study was conducted between December 2012 and March2013 in ART clinic of Kalawati Saran Children Hospital(KSCH), a tertiary care hospital for children and the only pediatric centre of excellence for HIV in Delhi, since 2011. The study involved a retrospective case review of 83 antiretroviral naïve CLHIV between 8 months to 13 years of age attending the pediatric ART clinic of this hospital and resident of Delhi. After the HIV infection was established on serological grounds, information on demographic characteristics, clinical manifestation and immunological profile of the CLHIV was extracted from our data base using a standardized questionnaire. Clinical and immunological stage ${ }^{4}$ were based on the WHO norms. WHO clinical stage 1 and clinical stage II were termed as early disease, while clinical stage III and IV as advanced disease. CD4 percentage was used to classify the immunological status of children below 5 years of age, while CD 4 count was used in children aged 5 years or older. ${ }^{4}$ Mode of HIV transmission was determined by establishing mother's HIV status, history of transfusion of blood or blood product and probable unsafe injection given to the children.
The diagnosis of tuberculosis was based on the WHO guidelines for National TB program forchildren ${ }^{5}$; cases were either smear positive or smear negative with clinical/radiological features were diagnosed to be TB positive. Other baseline investigations that were obtained were complete blood count, CD4 count, CD4 percentage, HBsAg and $\mathrm{HCV}$ assays. Anemia was defined using the WHO criteria: 6-59 months, <11g/dl; 5-11years, $<11.5 \mathrm{~g} / \mathrm{dl} ; 12-14$ years, $<12 \mathrm{~g} / \mathrm{dl} .^{6}$

Data was collected after obtaining approval from the institutional protocol and ethical committee. All consecutive children attending the centre during the study period and residents of Delhi were eligible for inclusion in the study if their caregivers gave consent and study subjects who were more than 7 years gave assent. Collected data was transformed into variables, coded, entered and analyzed using SPSS version 12. All observations were in terms of mean, median, standard deviation, percentages and proportions. Tests of significance like chi square, t-test were applied for comparisons wherever required. $P$ value less than 0.05 was considered statistically significant at $95 \%$ confidence level.

\section{RESULTS}

Eighty three antiretroviral naïve children were enrolled in the study. The mean and median ages of the children at the time of HIV diagnosis were $5.4 \pm 2.9$ yearsand 4.9 years (range 8 months to 13 years) respectively. There were $52(62.7 \%)$ boys. Father was the head of the family in the majority of the subjects $(68.7 \%)$, while one child was living in an NGO. Majority (74.7\%) belonged to upper lower Socio-economic class according to Kuppuswami scale CPI 2013. ${ }^{7}$ Twenty seven children (32.5\%) were orphaned, of whom $16(59.3 \%)$ and $11(40.7 \%)$ were single and double orphans respectively. Both parents were found to be positive in $63.9 \%$ of the CLHIV while mother was found to be positive in $69.9 \%$ and father was positive in $64.5 \%$ of the children. In 13 (15.7\%) CLHIV, siblings were also found to be positive. Mother was the primary caretaker in almost two-third of the children. Sociodemographic characteristics of CLHIV are shown in table 1. 


\begin{tabular}{|c|c|c|c|}
\hline \multicolumn{2}{|c|}{$\begin{array}{l}\text { Table1. Socio-Demographic Ch } \\
\text { Infected Children }(\mathrm{N}=83) \\
\text { Socio-demographic } \\
\text { characteristics }\end{array}$} & \multirow{2}{*}{$\begin{array}{r}\text { Number } \\
42 \\
\end{array}$} & \multirow{2}{*}{$\begin{array}{l}\% \\
50.6\end{array}$} \\
\hline \multirow{2}{*}{ Age } & Less than 5 years & & \\
\hline & Greater than 5 years & 41 & 49.4 \\
\hline \multirow{2}{*}{ Gender } & Male & 52 & 62.7 \\
\hline & Female & 31 & 37.3 \\
\hline \multirow{6}{*}{$\begin{array}{l}\text { HIV status } \\
\text { of parents }\end{array}$} & Mother positive & 58 & 69.9 \\
\hline & Father positive & 53 & 63.9 \\
\hline & $\begin{array}{l}\text { Both parents } \\
\text { positive }\end{array}$ & 53 & 63.9 \\
\hline & One parent positive & 5 & 6.0 \\
\hline & None positive & 19 & 22.9 \\
\hline & Siblings positive & 13 & 15.7 \\
\hline \multirow{2}{*}{ Orphaned } & Yes & 27 & 32.5 \\
\hline & No & 56 & 67.5 \\
\hline \multirow{5}{*}{$\begin{array}{l}\text { Primary } \\
\text { care taker }\end{array}$} & Mother & 63 & 75.9 \\
\hline & Father & 10 & 12.0 \\
\hline & Maternal relatives & 6 & 7.2 \\
\hline & Paternal relatives & 2 & 2.4 \\
\hline & Siblings & 2 & 2.4 \\
\hline
\end{tabular}

The most common route of HIV infection was mother-to-child (69.9\%). Blood transfusion and probable unsafe injections contributed $12.0 \%$ and $6.0 \%$ respectively. $71.1 \%$ of the children were in advanced (WHO clinical stage III and IV) stage and were in moderate to severe immuno-compromised stage (table 2). The most common symptoms seen in these children were fever $(74.7 \%)$, cough

Table 2. Mode of HIV Transmission, Clinical Staging and Immunological Staging In CLHIV (N=83)

\begin{tabular}{|c|c|c|c|}
\hline \multicolumn{2}{|c|}{ Mode of HIV transmission } & Number & $\%$ \\
\hline \multicolumn{2}{|c|}{ Mother to child } & 58 & 69.9 \\
\hline \multicolumn{2}{|c|}{ Blood /Blood products transfusion } & 10 & 12.0 \\
\hline \multicolumn{2}{|c|}{ Probable unsafe injection } & 5 & 6.0 \\
\hline \multicolumn{2}{|l|}{ Unknown } & 10 & 12.0 \\
\hline \multicolumn{4}{|c|}{ Clinical Staging } \\
\hline \multirow{2}{*}{$\begin{array}{l}\text { Early } \\
\text { disease }\end{array}$} & WHO Clinical Stage I & 3 & 3.6 \\
\hline & WHO Clinical Stage II & 21 & 25.3 \\
\hline \multirow{2}{*}{$\begin{array}{l}\text { Advanced } \\
\text { disease }\end{array}$} & WHO Clinical Stage III & 33 & 39.8 \\
\hline & $\begin{array}{l}\text { WHO Clinical Stage } \\
\text { IV }\end{array}$ & 26 & 31.3 \\
\hline \multicolumn{4}{|c|}{ Immunological Staging } \\
\hline \multicolumn{2}{|c|}{ Not Immunodeficient } & 7 & 8.4 \\
\hline \multicolumn{2}{|c|}{ Mild Immunodeficient } & 17 & 20.5 \\
\hline \multicolumn{2}{|c|}{$\begin{array}{l}\text { Moderate } \\
\text { Immunodeficient }\end{array}$} & 17 & 20.5 \\
\hline \multicolumn{2}{|c|}{ Severe Immunodeficient } & 42 & 50.6 \\
\hline
\end{tabular}

(56.6\%)and weight loss/failure to gain weight (34.9\%). Diarrhoea (56.6\%), pneumonia $(41.0 \%)$, popular pruritic eruptions (18.1), candidiasis (16.9\%) and tuberculosis (14.5\%) were the most common opportunistic infections seen in these children. Hepatitis $\mathrm{B}$ and $\mathrm{C}$ co-infections were seen in $6.0 \%$ and $2.4 \%$ of the children respectively.

Four out of five children were having hepatomegaly while anaemia was seen in three out of four children. Lymphadenopathy was seen in $72.3 \%$ of the children, mainly in cervical and axillary regions accounting for $57.8 \%$ and $43.4 \%$ of cases. Clinical features of CLHIV are shown in table 3. Mean CD4 $\%$ in children less than 5 years $(n=42)$ was $14.9 \pm$ 6.7 while mean $\mathrm{CD} 4$ count in children aged 5 years and above $(n=41)$ was $332.9 \pm 224.6$ cells $/ \mathrm{mm}^{3}$ (table 4).

\section{DISCUSSION}

In the present study, approximately two-thirds $(62.7 \%)$ of the study subjects were boys. Proportion of HIV positive boys in other studies in India was also more than $50 \%(63.4 \%-76 \%)$. $8,9,10,11$ According to National AIDS Control Organisation (NACO), mother to child transmission(MTCT) is the primary route of transmission for HIV among children. It is estimated that without any intervention, the risk of transmission of HIV from infected mother to her child is between, $20 \%$ to $45 \%$. ${ }^{12}$

In majority $(69.9 \%)$ of the study subjects, mothers were HIV positive, which is similar to findings in an earlier study conducted in New Delhi. ${ }^{9}$ This clearly shows that MTCT is the most common route of transmission. Hence preventive strategies need to be strengthened for preventing MTCT. Both parents were found to be HIV positive in nearly three fourth of the study subjects. Similar finding $(74 \%)$ was seen in a study conducted in Surat ${ }^{13}$, India while inChennai ${ }^{14}$, a relatively lower proportion $(38 \%)$ of HIV infected parents was observed indicating that mode of transmission may vary from place to place. Another study conducted by Okomo $\mathrm{U}$, et al in West Africa ${ }^{15}$, parents of $10.8 \%$ of children were HIV positive.

At the time of the study, both parents were alive in almost $65.6 \%$ of the study subjects while approximately $13.3 \%$ children had lost both parents. These findings were almost similar to another 


\begin{tabular}{|c|c|c|c|c|c|}
\hline \multirow[b]{2}{*}{ Clinical features } & \multirow{2}{*}{$\mathrm{N}(\%)$} & \multicolumn{2}{|c|}{ Immunodeficiency } & \multicolumn{2}{|c|}{$\mathrm{Cl}=95 \%$} \\
\hline & & No to Mild ( $n=24$ ) & $\begin{array}{c}\text { Moderate to Severe } \\
\qquad(n=59)\end{array}$ & $p$-value & OR \\
\hline \multicolumn{6}{|l|}{ Symptoms } \\
\hline Fever & $62(74.7)$ & 16 & 46 & 0.2 & $0.5(0.2-1.6)$ \\
\hline Cough & $47(56.6)$ & 11 & 36 & 0.2 & $0.5(0.2-1.4)$ \\
\hline Weight loss/failure to gain weight & $29(34.9)$ & 8 & 21 & 1.0 & $0.9(0.3-2.5)$ \\
\hline Rashes & $26(31.3)$ & 9 & 17 & 0.4 & $1.5(0.5-4.0)$ \\
\hline Ear discharge & $25(30.1)$ & 6 & 19 & 0.6 & $0.7(0.2-2.1)$ \\
\hline \multicolumn{6}{|l|}{ Opportunistic infections } \\
\hline Diarrhea & $47(56.6)$ & 8 & 39 & 0.0 & $0.3(0.1-0.7)$ \\
\hline Pneumonia & $34(41.0)$ & 7 & 27 & 0.2 & $0.5(0.2-1.4)$ \\
\hline Popular pruritic eruptions & $15(18.1)$ & 7 & 8 & 0.1 & $2.6(0.8-8.3)$ \\
\hline Candidacies & $14(16.9)$ & 2 & 12 & 0.3 & $0.4(0.1-1.7)$ \\
\hline Tuberculosis & $12(14.5)$ & 3 & 9 & 1.0 & $0.8(0.2-3.3)$ \\
\hline \multicolumn{6}{|l|}{ Other signs } \\
\hline Hepatomegaly & $68(81.9)$ & 17 & 51 & 0.1 & $0.4(0.1-1.2)$ \\
\hline Anemia & $65(78.3)$ & 12 & 53 & 0.0 & $0.1(0.0-0.3)$ \\
\hline Lymphadenopathy & $60(72.3)$ & 16 & 44 & 0.6 & $0.7(0.2-1.9)$ \\
\hline Splenomegaly & $48(57.8)$ & 13 & 35 & 0.8 & $0.8(0.3-2.1)$ \\
\hline Hepatosplenomagaly & $48(57.8)$ & 13 & 35 & 0.8 & $0.8(0.3-2.1)$ \\
\hline Failure to thrive & $10(12.0)$ & 2 & 8 & 0.7 & $0.6(0.1-2.9)$ \\
\hline Developmental delay & $8(9.6)$ & 2 & 6 & 1.0 & $0.8(0.2-4.3)$ \\
\hline
\end{tabular}

*multiple response

\begin{tabular}{|c|c|c|c|c|c|c|}
\hline \multirow[t]{2}{*}{ WHO clinical stage } & \multirow[t]{2}{*}{ Number (\%) } & \multicolumn{2}{|c|}{ CD4 } & \multicolumn{2}{|c|}{$\begin{array}{l}\text { WHO classification of } \\
\text { Immunodeficiency }\end{array}$} & \multirow[t]{2}{*}{$p$-value } \\
\hline & & Mean & SD & $\begin{array}{l}\text { Not significant } \\
\text { to Mild }\end{array}$ & $\begin{array}{l}\text { Moderate to } \\
\text { Severe }\end{array}$ & \\
\hline \multicolumn{7}{|c|}{ In children less than 5 years $(n=42)^{*}$} \\
\hline \multicolumn{7}{|c|}{ CD4 Percentage } \\
\hline Early & $13(31.0)$ & 18.9 & 7.4 & 7 & 6 & \multirow{2}{*}{0.00} \\
\hline Advanced & $29(69.0)$ & 13.1 & 5.7 & 3 & 26 & \\
\hline \multicolumn{7}{|c|}{ In children greater than 5 years $(n=41)^{* *}$} \\
\hline \multicolumn{7}{|c|}{ CD4 Count } \\
\hline Early & $11(26.8)$ & 586.5 & 232.7 & 10 & 1 & \multirow{2}{*}{0.00} \\
\hline Advanced & $30(73.2)$ & 239.9 & 132.7 & 4 & 26 & \\
\hline \multicolumn{7}{|c|}{ Opportunistic Infections $(\mathrm{N}=83)^{\star \star *}$} \\
\hline \multicolumn{7}{|c|}{ CD4 Percentage } \\
\hline $0-2$ & $38(45.8)$ & 16.2 & 7.4 & 6 & 32 & \multirow{2}{*}{0.04} \\
\hline$\geq 3$ & $45(54.2)$ & 12.2 & 6.0 & 1 & 44 & \\
\hline
\end{tabular}

* there was statistically significant association seen between clinical stage and immunodeficiency $(\mathrm{Cl}=95 ; \mathrm{p}=0.00)$; also there was statistically significant association between clinical staging and mean CD4 \% ( $p=0.02)$

** there was statistically significant association seen between clinical stage and immunodeficiency $(\mathrm{Cl}=95 ; \mathrm{p}=0.00)$; also there was statistical significant association between clinical staging and mean CD4 count $(p=0.00)$

*** there was significant statistical association seen between immunodeficiency and number of opportunistic infections $(p=0.04)$; also there was statistical significant association between the number of opportunistic infections and mean $\mathrm{CD} 4 \%(\mathrm{Cl}=95 ; \mathrm{p}=0.00)$ 
study in Delhi ${ }^{9}$ where both parents were alive in $58 \%$ instances and had expired in case of $8 \%$ of children. However in a study conducted by Patel et al ${ }^{13}$ both parents were alive in $40.8 \%$ of the cases, whereas one in four children had lost both parents. In another study by Pol, et a ${ }^{10}$ (Karnataka, 2007) $42 \%$ of children had single parent and $12.67 \%$ had lost both parents. Such differences can be attributed to availability, accessibility and utilization of ART services in differential study settings. The increased life expectancy of PLHIV with ART could also be one of the reasons for variation in these findings.

Loss of parents means not only loss of social security for these children but also adverse upbringing of children emotionally and financially. Nearly a third of $(29.1 \%)$ of children had lost their fathers, affecting the family economically which may have influenced medical treatment and regular follow up. These observations emphasize the family dimensions of the HIV infections. The increasing number of children orphaned due to HIVI AIDS is an emerging problem in many developing countries. ${ }^{9,10,13,15}$

As the most common route of transmission was vertical (MTCT), the gender distribution of CLHIV should have been almost equal (at least in the same proportion as the sex ratio at birth). Higher proportion of boys (62.7\%) could be due to low level of care and lower utilization of services for the infected girls.HIV infection in children is primarily restricted to perinatal transmission or is transfusion acquired. The present study has shown similar results, where MTCT was the most common route of transmission seen in $69.9 \%$ of the study subjects. Similar observations were made in other studies also. ${ }^{25}$

In spite of the fact that mandatory screening of donated blood for HIV antibodies has been in force since 1993 , it is seen that $12 \%$ of the study subjects had acquired HIV through transfusion of blood and blood products. However other studies, ${ }^{11,16,17}$ observed a higher percentage of children who had acquired HIV infection through blood/blood products $(19.3 \%$ - 39\%). Presuming adequate screening for anti-HIV antibodies, transmission of HIV may still be possible during the window period. This calls for more prudent usage of blood or blood products. Feasibility of antigen assays or
PCR assays to screen blood products for checking acquisition of transfusion mediated HIV also needs to be explored. Stringent quality control practices need to be instituted in HIV testing laboratories.

In the present study, it was seen that nearly three-fourth $(71.1 \%)$ of the study subjects were categorized as having moderate to severe disease (WHO clinical stage III \& IV). Similar observations were made by number of researchers ${ }^{13,18,19,20,21}$ who reported a significant proportion of children (started on HAART) to be suffering from moderate or severe form of disease $(31 \%-76 \%)$. 11 out of $83(13.3 \%)$ children were ambulatory, one was bedridden, while the rest of the study subjects $(85.5 \%)$ were in working functional status. The signs, symptoms and opportunistic infections were almost similar to those reported earlier from developed and developing countries, including India 11,17,22,23,24, although small variations can be attributed to the wide spectrum of disease all over the world. Management of these infections should be ensured in the ART clinics.

One of the important observations in this study was that CD4percentage and CD4 count declined with deterioration in the WHO clinical stages of HIV infection (table 3). Similar findings were also observed in a few other studies. ${ }^{25,26}$ This observation indicates that CD4 values are reliable marker of clinical status. With deteriorating immunity, there is worsening of clinical staging and increase in opportunistic infections. Children with lower CD4 values had more opportunistic infections as compared to children with better values of CD4 count who had no or less opportunistic infections and these findings have been reported in other studies ${ }^{22,25,26} \mathrm{CD} 4$ estimation has been studied as a marker of deterioration of HIV status and it is also a measure of relative risk of developing opportunistic infections in HIV positive children. Therefore CD4 values can be considered as a reliable marker of HIV progression. However there is a need of further studies on CD4 estimation in relation to antiretroviral therapy.

Limitations: Since it was a cross-sectional study, the response of HAART on immunodeficiency and morbidity cannot be assessed. Also viral load as a predictor of illness have not been studied. Moreover the results of this study in limited setting in Delhi cannot be generalized. However, association 
of immunological stage with clinical stage and opportunistic infections warrants further longitudinal studies in larger cohort.

Recommendations: As MCTC is a major route of acquiring HIV infection in children, emphasis must therefore be laid on PMTCT guidelines, investigations and treatment in pregnant mothers to prevent or reduce risk of HIV transmission to their children. There should also be more judicious usage of blood or blood products as even if we presume adequate screening for HIV infection, transmission may still be possible during the window period. Use of PCR assays or antigen assays for screening blood products before transfusion also needs to be considered. There should also be strict quality control practices in HIV testing laboratories and blood banks to prevent blood transfusion of HIV. Clinical manifestations and opportunistic infections of HIV infection are variable and mimic a number of other ailments. A high index of suspicion and appropriate investigation may help in early diagnosis. Training of paediatricians should also be organized on this subject for early diagnosis and management of HIV, related illnesses and opportunistic infections. Those children on treatment should be regularly followed up for drug adherence and treatment outcomes.

\section{REFERENCES}

1. UNAIDS. UNAIDS Report on the Global AIDS Epidemic: World Health Organization, Geneva, Switzerland; 2013. [Internet] Available from: http://www.unaids.org/sites/default/files/en/ media/unaids/contentassets/documents/ epidemiology/2013/gr2013/UNAIDS_Global_ Report_2013_en.pdf (last accessed on 21-052015)

2. Department of AIDS Control. Annual Report 20122013. Ministry of Health and Family Welfare: National AIDS Control Organization, Government of India, New Delhi. [Internet] Available from: http:// www.naco.gov.in/upload/Publication/Annual\%20 Report/Annual\%20report\%202012-13_English.pdf (last accessed on 21-05-2015)

3. Ministry of Health and Family Welfare, National AIDS Control Organization. Technical report India HIV Estimates - 2012: Government of India, New Delhi.

4. National AIDS Control Organization. Guidelines for HIV Care and Treatment in Infants and Children:
Government of India, New Delhi; 2006. [Internet] Available from: http://apps.who.int/medicinedocs/ documents/s18022en/s18022en.pdf (last accessed on 21-05-2015)

5. Guidance for national tuberculosis programmes on the management of tuberculosis in children: WHO;2006

6. WHO, UNICEF, UNU. Iron deficiency anemia: assessment, prevention and control, a guide for programme managers. Geneva, World Health Organization, 2001. [Internet] Available from: http:// www.who.int/nutrition/publications/micronutrients/ anaemia_iron_deficiency/WHO_NHD_01.3/en/ (last accessed on 21-05-2015)

7. Vijaya K, Ravikiran E. Kuppuswamy's SocioEconomic Status Scale-Updating Income Ranges for the Year 2013. NJRCM 2013 JulySept;2(2):79-148

8. Choudhary N, Gomber S, Narang M. Clinicoimmunological profile and outcome of antiretroviral therapy in HIV-positive children. Public Health Nutrition 2012;15(8):1442-1445

9. Arun S, Singh AK, Lodha R, Kabra SK. Disclosure of the HIV Infection Status in Children. Indian J Pediatr 2009;76(8):805-808

10. Pol RR, Shepur TA and Ratageri VH. ClinicoLaboratory Profile of Pediatric HIV in Karnataka. Indian J Pediatr 2007;74(12):1071-1075

11. Sehgal R, Baveja UK, Chattopadhya D, Chandra J and Lal S. Pediatric HIV Infection.Indian J Pediatr 2005;72(11):925-930

12. Operational Guidelines for Lifelong ART for all Pregnant Women Living with HIV for Prevention of Parent-to-Child Transmission (PPTCT) of HIV in India. National AIDS Control Organization, Government of India, New Delhi. [Internet] Available from: https://www.google.co.in/url?sa=t $\& r c t=j \& q=\& e s r c=s \& s o u r c e=w e b \& c d=4 \&$ cad $=r j a \&$ uact $=8 \&$ ved $=0 \mathrm{CDEQFjAD \& url}=\mathrm{http} \% 3 \mathrm{~A} \% 2 \mathrm{~F} \% 2 \mathrm{~F}$ karhfw.gov.in $\% 2$ Fnrhm $\% 2 F K S A P S \% 2 F O$ peratio nal $\% 2520$ Guidelines $\% 2520$ for $\% 2520$ PPTCT $\% 2$ 520program\%2520in\%2520India.\%2520Decemb er\%25202013.doc\&ei=809cVdXQJIOT8QWx5oG oAw\&usg=AFQjCNEgulXjsoo5aZsil_sb-SHuhgpC UA\&sig2 $=$ CmcmN9T5zSba3CINuYsMFg\&bvm $=b v$ .93756505, d.dGc (last accessed on 21-5-2015)

13. Patel A, Trivedi SS, Chudasama RK, Patel PK. Effect of antiretroviral therapy on clinical and immunologic disease progression in HIV positive 
children: One-year follow-up study. J Family Community Med 2012;19(3):178-183

14. Rajasekaran S, Jeyaseelan L, Raja K, Ravichandran N. Demographic \& clinical profile of HIV infected children accessing care at Tambaram, Chennai , India. Indian J Med Res 2009;129:42-49

15. Okomo U, Togun T, Oko F, Peterson K, Townend J, Peterson I, et al. Treatment outcomes among HIV1 and HIV-2 infected children initiating antiretroviral therapy in a concentrated low prevalence setting in West Africa. BMC Pediatr 2012;12:95

16. Lodha R, Upadhyay A, Kapoor V, Kabra SK. Clinical Profile and Natural History of Children with HIV Infection. Indian J Pediatr 2006;73(3):201-204

17. Dhurat $R$, Manglani M, Sharma R, Shah NK. Clinical spectrum of HIV infection. Indian Paediatrics 2000;37:831-836

18. Kabue MM, Buck WC, Wanless SR, Cox CM, McCollum ED, Caviness AC, et al. Mortality and clinical outcomes in HIV-infected children on antiretroviral therapy in Malawi, Lesotho, and Swaziland. Pediatrics 2012;130(3):591-599

19. Biadgilign S, Deribew A, Amberbir A, Deribe K. Adherence to highly active antiretroviral therapy and its correlates among HIV infected pediatric patients in Ethiopia.BMC Pediatrics 2008;8:53

20. Gebremedhin A, Gebremariam S, Haile F, Weldearegawi B, Decotelli C. Predictors of mortality among HIV infected children on anti- retroviral therapy in Mekelle Hospital, Northern Ethiopia: a retrospective cohort study.BMC Public Health 2013;13:1047

21. Shet A, Mehta S, Rajagopalan N, Dinakar C, Ramesh E, Samuel NM, et al. Anemia and growth failure among HIV-infected children in India: a retrospective analysis. BMC Pediatrics 2009;9:37

22. Ylitalo N, Brogly S, Hughes MD, Nachman S, Dankner W, Van Dyke R, et al. Risk factors for opportunistic illnesses in children with human immunodeficiency virus in the era of highly active antiretroviral therapy. Arch PediatrAdolesc Med. 2006;160(8):778-787

23. Ramos AN, Matida LH, Hearst N, Heukelbach J. Opportunistic illnesses in Brazilian children with AIDS: results from two national cohort studies, 1983-2007

24. Kabue MM, Buck WC, Wanless SR, Cox CM, McCollum ED, Caviness AC, et al. Mortality and clinical outcomes in HIV-infected children on antiretroviral therapy in Malawi, Lesotho, and Swaziland. Pediatrics 2012;130(3):591-599

25. Agarwal D, Chakravarty J, Sundar S, Gupta V, Bhatia BD. Correlation between Clinical Features and Degree of Immunosuppression in HIV Infected Children. Indian Pediatrics 2008;45:140-143

26. Chakravarty J, Mehta H, Parekh A, Attili SV, Agarwal NR, Singh SP, et al. Study on clinicepidemiological profile of HIV patients in eastern India. J Assoc Physicians India 2006;54:854-857. 